\title{
Literature Review of Listening Effort Using Subjective Scaling
}

\author{
Jihyeon Lee, Seungwan Lee, Woojae Han, and Jinsook Kim \\ Department of Speech Pathology and Audiology, Graduate School, Hallym University, Chuncheon, Korea
}

\author{
주관적 측정을 이용한 청취 노력의 문헌 고찰 \\ 이지현 · 이승완 · 한우재 · 김진숙 \\ 한림대학교 일반대학원 언어병리청각학과
}

\author{
Received December 7, 2016 \\ Revised February 23, 2017 \\ Accepted March 1, 2017 \\ Address for correspondence \\ Woojae Han, PhD \\ Department of Speech Pathology and \\ Audiology, Graduate School, \\ Hallym University, \\ 8603, Natural Science Building, \\ Hallym Daehakgil 1, \\ Chuncheon 24252, Korea \\ Tel +82-33-248-2216 \\ Fax $+82-33-256-3420$ \\ E-mail woojaehan@hallym.ac.kr
}

Listening effort is defined as a listener's mental exertion required to understand a speaker's auditory message, especially when distracting conditions are present. This review paper analyzed several subjective scaling tools used to measure the listening effort in order to suggest the best tool for use with hearing-impaired listeners who have to expend much effort even in everyday life. We first explained the importance of measuring listening effort and discussed various kinds of measurements. We then analyzed and categorized 15 recently published articles (i.e., from 2014 to 2016) into three topics: performance and listening effort, listening effort and fatigue, and clinical implication of listening effort. We compared the articles in terms of pros and cons and also identified 10 tools for use in the subjective scaling. Although none of these tools were unified or standardized easily, we concluded that 7-point scale would be the most reasonable as a less time-consuming measurement for compartmentalizing the degree of listening effort. If used with objective tools for measuring the listening effort, the subjective scaling could be a powerful tool for clinical use.

Korean J Otorhinolaryngol-Head Neck Surg 2017;60(3):99-106

Key Words Attention - Clinical implication · Fatigue · Listening effort · Subjective scaling.

\section{서 론}

과거의 이과학·청각학적 연구들은 청력손실로 인해 난청인 들의 어음인지 능력이 얼마나 저하되었는지 정확하게 평가하 고 진단하는 데 초점을 맞춰왔다. 또한, 보청기 착용 및 인공 와우 이식 후 난청인들의 어음인지 능력 향상을 위해 다양한 재활 방법들을 적용해 왔다." 특히, 인공와우 이식 수술의 건 강의료보험 지원범위가 점차 확대되면서 선천적 혹은 유전 적 난청을 가진 영·유아는 물론 후천적으로 청력손실을 진단 받은 장·노년기 난청인들의 인공와우 이식 건수가 점차 증가 하였고, 이식 후 그들의 효율적인 청능 훈련에 대한 연구들 이 많이 보고되고 있다. ${ }^{2)}$

보다 최근에는 어음인지 능력의 정확한 측정법 및 향상률에
대한 연구뿐 아니라, 어려운 듣기 환경에서 다양한 소리와 어 음을 이해하기 위해 난청인들에게 요구되는 청취 노력 혹은 집중 여부에 대한 관심이 높아지고 있다. 청취 노력(listening effort)이란 청각적 메시지에 주의를 기울이고 이해하는 데 필 요한 정신적 노력을 일컫는다. ${ }^{3.4}$ 청취 노력을 측정하는 연구 자들은 난청인들이 정상 청력을 지닌 사람과 유사한 어음인 지도를 갖기 위해 청취 노력을 너무 많이 기울이면 십게 피로 감을 느끼게 되어, 어려운 듣기 환경에 대한 적응이 오히려 저 해된다고 주장하였다.5,6) 따라서 보청기 및 인공와우 적합 시 향상된 어음인지도를 보이더라도 많은 청취 노력이 요구된다 면 이는 적절한 적합이라고 보기 어려우며) 궁극적으로는 임 상에서도 난청인을 대상으로 어음인지도 및 청취 노력의 균형 을 적절히 맞추기 위한 노력이 필요하겠다. 
최근 출간되고 있는 청취 노력에 관한 국외 문헌들은 측정 도구에 따라 크게 세 부분으로 구분할 수 있다: 1) 주관적인 척도 혹은 반응 시간을 이용한 행동적 측정, ${ }^{899}$ 2) 전기생리적 측정법을 이용한 객관적 반응의 측정 ${ }^{10,11}$ 3) 영상기법을 이용 한 뇌에서의 관여 위치 측정. ${ }^{12,13)}$ 예를 들어, Dawes 등8)은 신규 보청기 착용자들의 보청기 적응 후 청취 노력의 변화를 주관적 으로 측정하기 위해, 양이 청취 혜택을 평가할 수 있는 Speech, Spatial, and Quality of Hearing Scale(SSQ) 설문 문항들 ${ }^{14}$ 중 청취 노력과 연관된 문항만을 추출하여 새로이 척도를 제 시하였다. Houben 등흔 어음명료도와 동시에 어음을 듣고 반응하는 시간을 측정하였는데, 그 결과 신호대잡음비(signalto-noise ratio, SNR)가 낮아질수록 어음명료도가 $100 \%$ 로 동일하더라도 반응 시간이 길어져서, 건청인도 배경 소음이 높으면 더 높은 청취 노력이 요구되었음을 확인하였다. 이 외 에도 보청기의 방향성 마이크 및 소음감소 기능 적용 시 청취 노력의 변화, ${ }^{15-17)}$ 또는 인공와우 착용 후 청취 노력의 변화 ${ }^{18)}$ 에 관하여 주관적인 설문 기법이 연구에 적용되었다. ${ }^{14,19,20)}$ 전기 생리적 반응의 측정 예로, Kramer 등이은 높은 신호대잡음비 상황에서 어음인지 과제를 수행하는 중 청각적 처리능력이 증 가하면 청자의 동공 확장(pupil dilation) 정도가 유의미하게 증가한다고 보고하였고, 다채널의 사건관련전위(event-related potential)를 활용한 연구 ${ }^{21}$ 에서는 중추청각기관이 청취 노력 에 직접적으로 관여한다는 것을 확인하였다. 한편, 기능적 자기 공명영상(functional magnetic resonance imaging)을 적용한 Wild 등ㄹㅇㅢ 연구에서는 어음 청취 시 청자의 전두부가 활성화 되지만 어음인지도가 저하되어도 이 영역의 활성화가 감소하 지 않음을 확인하여 전두부를 청취 노력의 신경학적 지표라 고 제안하였다.

청취 노력의 다양한 측정법 중에서도 척도를 이용한 주관적 인 측정법은 피검자의 주관성이 반영되어 자기보고 편향 혹 은 문항 정의 차이에 의한 왜곡이 나타날 수 있다는 단점이 있다. 하지만 이는 객관적 측정법과 함께 실행되면 보완이 가 능하고, 쉽고 빠르게 청취 노력의 정도를 측정할 수 있으며 결과 해석이 용이하다는 장점을 가지고 있기 때문에 연구자 및 임상가들에게 큰 호응을 얻고 있다. 따라서 본 논문에서는 청취 노력에 관하여 국외에서 최근 2년간(2014 2016년) 출간 된 선행 논문 15 편을 중심으로 주관적인 척도 측정법에 관 하여 장·단점을 비교 및 분석하여, 난청인들의 청취 노력을 잘 반영할 수 있는 측정법을 제안하고자 한다.

\section{본 론}

본 종설에서 언급한 선행 논문들은 주제에 따라 '수행력과
청취 노력의 관계', '청취 노력과 피로의 관계', '청취 노력의 임 상적 적용으로 분류하고, 각 주제 내에서 논문들을 비교·분 석하였다.

\section{수행력과 청취 노력의 관계}

집중, 기억, 또는 동기 부여 상황 아래에서의 수행력과 청취 노력 사이의 관계에 대한 연구가 이루어졌다. 먼저 청취 방법 에 따른 능동적 혹은 수동적 청취 노력의 영향을 사건관련 전위로 분석한 Erlbeck 등 ${ }^{22}$ 의 연구는 18 명의 건청인들에게 '자극을 집중하여 듣기', '자극을 수동적으로 듣기', '자극을 무 시하기'의 세 가지 지시 사항을 제시한 후, 청각 인지를 객관적 으로 검사하는 부정합음성도(mismatch negativity)와 N400 반응을 측정하였다. 또한 각 조건별 자극 제시 이후, 연구대 상자들이 기여한 청취 노력의 정도를 주관적으로 표시하도 록 요구하였다. 청취 노력 정도를 0 220까지 척도화하고 7개 의 간격으로 구분하였다. 20 단계는 '거의 노력하지 않음'을 뜻 하고, 205단계에서는 '비범한 노력을 기울임'으로 청취 노력 을 표기하였다. 분석 결과, 사건관련전위의 객관적인 결과와 청취 노력의 주관적 측정 간 높은 양의 상관관계를 보여주었 다. 즉, 자극을 집중하여 듣거나 수동적으로 들을 시 부정합 음성도와 N400 모두에서 큰 진폭을 나타내었고, 이 조건에서 연구대상자들은 높은 청취 노력이 필요하다고 표기하였다. 반 면, '자극을 무시하기' 조건 시 사건관련전위에서의 진폭과 청 취 노력 측정 수치가 모두 낮게 나타났다. 그러나 사용된 척 도는 220단계로 표기된 척도와 7개의 척도 구분을 왜 따로 기재하였는지에 관한 명확한 설명이 없었으며, 0 220까지의 표기가 연구대상자가 기울인 청취 노력의 정도를 선택할 때 오히려 혼란을 줄 가능성이 높아 보였다.

한편, 동기의 변화가 청취 노력의 주관적 평가 및 대처 전략 사용 가능성에 미치는 영향을 확인한 연구에서도 주관적 척 도 평가를 사용하였다. ${ }^{23}$ 연구자들은 60 명의 건청인들을 대상 으로 청각만 자극하는 조건과 청각과 시각을 동시에 자극하 는 조건에서 소음하 문장검사를 시행하였다. 문장 제시 후, 연 구대상자들은 각 조건에서 요구된 청취 노력의 정도를 표기하 였다. 주관적 척도 평가 문항은 기존의 SSQ 설문지에서(1) 청취 노력과 관련된 4 개의 문항만을 추출하여 사용하였다. 즉, 문 항의 특성은 청취 노력, 청취 피로, 회피, 통제로 구분하였고, 각 문항에 대한 질문 제시 후 해당 정도를 0 10 척도로 표기 하도록 요구하였다. 척도에서 0은 'very '(매우 )를 의미하고 10은 'not at all '(전혀 않다)을 의미하였다. 이 연구에서 사용 한 주관적 척도 평가지는 각 실험 조건당 청취와 관련된 노력, 피로, 회피, 통제로 세분화하여 연구대상자의 청취 노력의 기 여 여부를 다양하게 분석한 점은 좋으나, 척도가 10 점으로 
구분이 너무 많고 척도 중간중간에 척도가 의미하는 정도를 표기하지 않아 정확한 측정 및 분석에 다소 저해될 것으로 생각된다. 이에 반해, 명료도 지표의 하나인 음성전송지수 (speech transmission index)의 예측을 위해 청취 노력과 어음 인지도에 대한 소음과 반향의 결합 효과를 비교한 Rennies 등 ${ }^{24)}$ 의 연구에서는 2010년 Luts 등 ${ }^{25)}$ 의 연구에서 사용한 주관적 측정법과 동일한 주관적인 청취 노력의 척도를 적용하였지만 청취 노력을 13 단계로 척도화하고 중간에 7 개의 표시를 설정 하여 연구대상자에게 정도화에 대한 제시를 명확하게 하였다 (Fig. 1). 연구자들은 음성전송지수가 증가할수록 청취 노력 이 감소하고 동일한 음성전송지수를 갖더라도 소음만 있는 조건보다는 반향만 있는 조건에서 청취 노력이 더 낮아짐을 확인하였다.

자기보고 방식과 단어 기억 검사를 임상적 청력검사 절차에 포함하는 것이 적합한지 평가하고자 30명의 건청인을 대상으 로 실험한 Johnson 등 ${ }^{26)}$ 의 연구 역시, 어음인지도 측정을 위 해 소음하 문장검사를 실시하였고, 문장 제시 후 청취 노력 에 대한 주관적인 평가로 7점 척도를 사용하였다. Fig. 2는 Schulte 등 ${ }^{27)}$ 의 연구에서 기존에 사용했던 13점 척도를 7점으 로 재설정하여 적용하였다. 이는 Rennies 등 ${ }^{24}$ 의 연구에서 사 용한 주관적 척도 평가지와 매우 유사하였으며 어음인지도 점수가 청취 노력의 반영 여부, 청취 노력의 자기보고와 단어 회상법이 유사한 정보를 제공하는지, 두 측정법이 청취 노력 측정에 유효한지, 어떤 방법이 청취 노력의 변화에 더 민감한 지 등에 대하여 연구하였다. 연구 결과, 더 어려운 신호대잡음 비와 예측도가 낮은 문장 조건에서 높은 자기보고 평가와 낮 은 단어 회상이 나타나 일반적으로 더 어렵다고 생각되는 상
황에서 실제로 더 많은 노력이 필요함을 확인하였다. 또한 7점 척도를 활용하는 것이 주관적인 청취 노력을 검사하는 데 용 이하며 수집된 정보를 분석하는 것에서도 신뢰적임을 시사하 였다.

\section{청취 노력과 피로의 관계}

많은 청취 노력으로 인해 청자가 피로를 느낀다는 것은 당 연한 인과관계이다. 여러 연구자들은 청력손실과 관련된 청 취 노력은 물론, 피로에 대한 정의와 다양한 평가 방법들을 기술하였다." 사전적 의미로 '듣는다'라는 동사는 '소리에 집 중하는 것'이고, '노력'은 신체적 또는 정신적 활동'으로 명명 할 수 있다. 이러한 사전적 정의에 기초하여, 청취 노력은 청각 적 메시지에 집중하고 이해하는 데 요구되는 정신적 노력으로 정의될 수 있다. 따라서 청취 노력은 1) 저하된 신호 상황이나 2) 배경 소음, 반향, 보청기 신호 처리와 같은 소리 전달의 방 해가 있을 시, 혹은 3) 청각 장애, 비원어민과 같은 청취자의 내적 한계가 있을 때 더욱 많이 요구된다. ${ }^{28)}$ 그러나 이러한 방 해는 지속적인 배경 소음이 있어도 화자의 얼굴을 보는 시각 적 단서로 어느 정도 줄일 수 있다. ${ }^{29)}$ 한편, 피로는 '정신적 또 는 신체적 노력으로 야기되는 극심한 피곤'으로 정의된다. 앞 서 정의한 청취 노력의 정의에 따라 피로는 정신적 노력인 청 취 노력과 연결될 수 있고, 난청인들이 증가된 청취 노력으로 인한 높은 피로를 보고하는 것은 당연하다. 이러한 이유로 McGarrigle 등 ${ }^{4)}$ 은 청취 노력과 피로 모두 자기보고와 행동 및 생리적 측정으로 평가할 수 있다고 서술하였다. 청취 노력 과 마찬가지로 피로 역시 척도 또는 설문지의 형태로 자기보 고 될 수 있다. ${ }^{30,31)}$ 예를 들어, 난청과 건청 근로자들을 대상

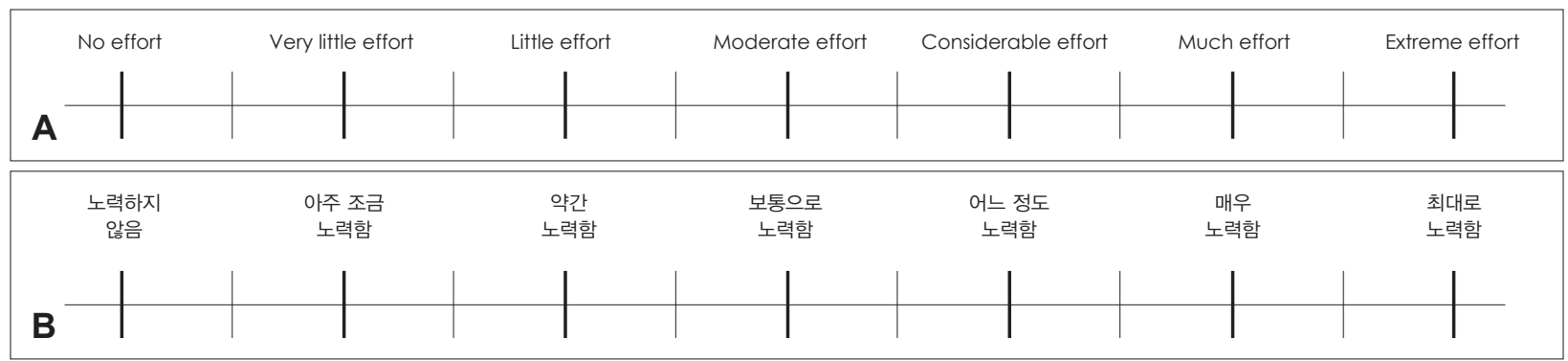

Fig. 1. 13-point scale for listening effort used by Rennies, et al. ${ }^{24)}$ Inferred English version (A) and its translation in Korean (B).

\begin{tabular}{|ll|ll|}
\hline \multicolumn{1}{|c|}{ Listening Effort Scale } & & \multicolumn{1}{c|}{ 청취 노력 척도 } \\
\begin{tabular}{llll} 
1. No effort & 5. Considerable effort & 1. 노력하지 않음 & 5. 어느 정도 노력함 \\
2. Very little effort & 6. Much effort & 2. 아주 조금 노력함 & 6. 매우 노력함 \\
3. Little effort & 7. Extreme effort & 3. 약간 노력함 & 7. 최대로 노력함 \\
4. Moderate effort & & 4. 보통으로 노력함 & \\
\hline
\end{tabular}
\end{tabular}

Fig. 2. 7-point scale of listening effort used by Johnson, et al ${ }^{26)}$ Original version in English (A) and its translation by Korean (B). 
으로 직업적 수행도에 대한 난청의 영향을 평가한 연구에서 청취 노력과 피로도를 간단한 설문과 4점 척도를 사용하여 조사하였을 때, 난청 근로자들이 건청 근로자보다 피로나 정 신적 괴로움의 이유로 더 자주/많이 병가를 내는 것으로 분석 되었다. ${ }^{31)}$ 또한 Nachtegaal 등 ${ }^{30}$ 의 연구에서는 직장의 전반적 인 평가와 경험을 기초로 한 설문지로부터 11 개 항목을 추출 하여 제작한 척도로 난청인들이 직장에서 경험하는 피로를 평 가하였다. 이 연구에서는 예상했던 대로 난청 근로자들이 건청 근로자보다 회복에 더 많은 시간이 필요하다고 보고하였다.

청취 피로는 성인은 물론 학령기 아동의 수행력에도 부정 적인 영향을 줄 수 있다. ${ }^{32)}$ 예를 들어, 난청 성인이 정상 성인보 다 직장에서 더 많은 스트레스와 피로를 경험하며, 이로 인해 업무 수행뿐 아니라 삶의 질에도 영향을 받을 수 있다. 동일 하게 아동의 경우에도 수업 중 내용에 대한 과도한 집중으로 인해 육체적, 정신적 스트레스를 받고 쉽게 피로해지며, 교실 에 존재하는 과도한 소음 수준은 아동의 청취를 방해하고 더욱 피로감을 느끼게 한다. 따라서 학업 능력 감소, 학교 결 석 증가, 일상생활에서 의욕 부족, 수면 부족, 사회적 관계 변 화, 삶의 질에 대한 부정적 변화 등이 일어날 수 있다고 관련 연구자들은 지적하였다. 이러한 성인과 아동이 일상생활에 서 경험하는 정신적 노력을 평가할 수 있는 방법으로는 시각 적 아날로그 척도와 설문지가 있다. Mackersie 등미는 주관 적 청취 노력을 측정하기 위해 National Aeronautic and Space Administration(NASA)에서 개발한 NASA-TLX(Task Load Index $)^{19)}$ 를 수정하여 사용하였다. 또한 Rudner 등 ${ }^{33)}$ 은 Visual Analog Scale을 소개하고, 이를 보청기 착용 후 소음하 어음 인지도 검사 시 청취 노력에 영향을 줄 수 있는 작업기억 용 량에 대한 연구에 적용하였다. 이와 같은 주관적인 측정법은 앞서 설명했듯이 개인적 인지를 평가하는 것이 쉽고 빠르며 타당도가 높은 측정법이다.

\section{청취 노력의 임상적 적용}

난청인들의 청취 노력 정도를 측정하여 난청의 영향을 확인
하고 보청기 또는 인공와우 기술을 평가하는 것을 목적으로 하는 논문들이 최근 다수 발표되고 있다. Brons 등 ${ }^{15)}$ 은 보청 기의 단일 마이크 소음감소 기능의 지각적 효과를 평가하기 위해 어음인지도뿐 아니라 청취 노력을 9점 척도를 적용하여 분석하였다(Fig. 3). 대상자는 20명의 중도 감각신경성 난청인 들로, 건청인 대상의 이전 연구 ${ }^{16)}$ 데이터와의 비교를 통해 청 취 노력에 대한 난청의 영향을 확인하였다. 연구 결과, $-4 \sim+4$ $\mathrm{dB}$ 신호대잡음비의 배경 소음 상황에서 난청인들의 어음인지 도는 건청인에 비해 더 낮고 청취 노력 또한 더 많이 요구되었 다. 이는 소음 상황에서 난청인이 청력손실로 인해 저하된 어 음인지 능력을 보상하기 위해 청취에 더 많은 노력을 기울인 다는 것을 시사한다. Desjardins ${ }^{6}$ 는 상업적으로 사용되고 있 는 보청기의 방향성 마이크와 소음감소 알고리즘의 독립적 또는 결합된 영향을 소음하 어음인지 상황에서 난청 노인들 의 청취 노력을 객관적 및 주관적으로 평가하였다. 연구에 사 용된 듣기 상황은 조용한 상황과 SNR이 서로 다른 4가지 소 음 상황이었으며, 각 조건 제시 후 Johnson 등 ${ }^{26)}$ 과 동일한 7 점 척도 평가를 적용하여 어음인지 시 얼마나 힘들었는지 표 시하도록 하였다(Fig. 2). 연구 결과, 주관적 청취 노력과 청취 조건에는 유의미한 관계가 있었다. 즉, 조용한 상황에서 인지 된 청취 노력이 다양한 소음 조건하에서 요구된 청취 노력보 다 더 낮았다.

Schnabl 등 ${ }^{18)}$ 은 양이 인공와우 착용자 34 명과 단이 인공와 우 착용자 38 명에게 조용한 상황, $\mathrm{TV}$ 배경 소음 정도의 적은 소음 상황, 시끄러운 레스토랑의 소음 상황에서 자기보고된 청취 노력의 정도를 비교하였다. 각 상황에서 짧은 질문 및 5 분 정도의 텍스트와 10 분 정도의 긴 이야기를 제시한 후, 연 구대상자들은 설문에 대한 간단한 설명을 듣고 6점 척도로 개발된 설문지를 작성하였다(Fig. 4). 연구 결과, 청취 노력 정도는 배경 소음의 강도와 청취 시간에서는 유의미한 차이 를 보였지만, 양이와 단이 착용자 그룹 간 차이는 유의미하지 않았다. 즉, 양이에 인공와우를 착용할 경우 청취 노력을 약 간 감소시킬 수 있지만, 단이 인공와우 착용 시 감소되는 정도

\begin{tabular}{|c|c|c|c|c|}
\hline $\begin{array}{c}\text { Complete relaxation } \\
\text { possible; } \\
\text { no effort required }\end{array}$ & $\begin{array}{c}\text { Attention necessary; } \\
\text { no appreciable } \\
\text { effort required }\end{array}$ & $\begin{array}{c}\text { Moderate } \\
\text { effort required } \\
\end{array}$ & $\begin{array}{l}\text { Considerable } \\
\text { effort required }\end{array}$ & $\begin{array}{l}\text { No meaning } \\
\text { understood with } \\
\text { any feasible effort } \\
\end{array}$ \\
\hline A & 1 & 1 & | & 1 \\
\hline $\begin{array}{c}\text { 편안하게 완료함; } \\
\text { 노력이 전혀 } \\
\text { 요구되지 않음 }\end{array}$ & $\begin{array}{l}\text { 집중 필요; } \\
\text { 노력이 별로 } \\
\text { 요구되지 않음 }\end{array}$ & $\begin{array}{l}\text { 보통 정도의 } \\
\text { 노력이 요구됨 }\end{array}$ & $\begin{array}{c}\text { 상당한 } \\
\text { 노력이 요구됨 }\end{array}$ & $\begin{array}{l}\text { 아무리 노력해도 } \\
\text { 의미를 } \\
\text { 이해할 수 없음 }\end{array}$ \\
\hline 1 & 1 & 1 & 1 & 1 \\
\hline B & 1 & 1 & I & 1 \\
\hline
\end{tabular}

Fig. 3. 9-point scale used by Brons, et al. ${ }^{15)}$ Inferred English version (A) and its translation by Korean (B). 


\begin{tabular}{|c|c|c|c|}
\hline & Antwortmöglichkeiten zu jeder Frage & & 각 질문에 가능한 답변 \\
\hline & 1. Keine Anstrengung erforderlich & & 1. 노력이 필요하지 않음 \\
\hline & 2. Minimale Anstrengung & & 2. 약간의 노력이 요구됨 \\
\hline & 3. Mä B ige Anstrengung & & 3. 보통의 노력이 요구됨 \\
\hline & 4. Erhebliche Anstrengung & & 4. 어느 정도의 노력이 요구됨 \\
\hline & 5. Sehr gro $B$ e Anstrengung & & 5. 매우 많은 노력이 요구됨 \\
\hline A & 6. Ich kann trotz rö B ter Anstrengung Nicht so lange zuhören & B & 6. 최선의 노력에도 불구하고 듣지 못함 \\
\hline
\end{tabular}

Fig. 4. Original version by German (A) and its translation by Korean (B) applied for Schnabl, et al. ${ }^{18)}$

Q. How much effort you thought you had to expend to be able to understand a set of target sentences?

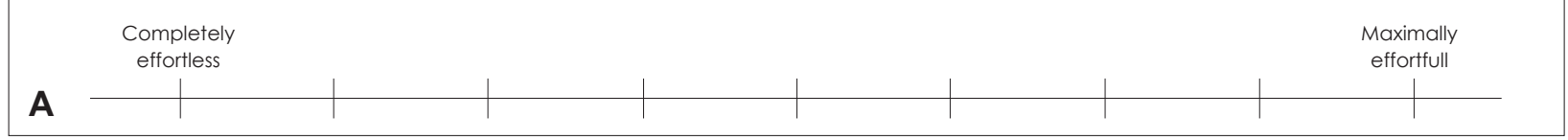

Q. 목표 문장들을 이해하는 데 얼마나 많은 노력을 기울였다고 여기십니까?

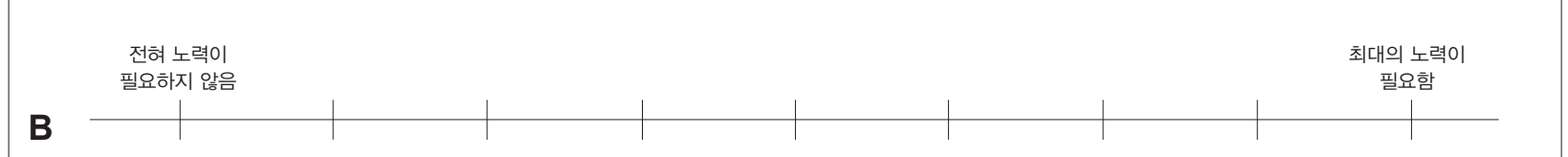

Fig. 5. Subjective 9-point scale for listening effort applied for Neher, et al. ${ }^{35)}$ Inferred English version (A) and its translation by Korean (B).

와 크게 다르지 않았다. 이러한 인공와우 착용자 간의 연구 뿐만 아니라, 인공와우 착용자와 보청기 착용자 간의 주관적 인 청취 노력을 비교한 연구 또한 진행되었다. Dwyer 등 ${ }^{34)}$ 은 일측성 난청을 가진 사람이 좋은 쪽 귀로 듣는 방법을 평가 하고자 66명의 연구대상자(정상 청력 30명, 인공와우 착용자 20 명, 보청기 착용자 16 명)에게 일상적인 듣기 상황 내 난청의 영향과 관련된 49개 문항을 10점 척도로 평가하는 $\mathrm{SSQ}$ 설 문지를 적용하였다. 그 결과, 건청인과 비교 시 일측성 난청을 가진 난청인은 모든 영역에서 더 많은 청취 노력이 필요하였고, 더 나은 귀로 듣는 방법(정상, 인공와우, 보청기)과 상관없이 한 쪽 귀에 의존하는 성인은 일상생활에서 듣기와 의사소통의 모 든 측면에서 불리하였다.

한편, Neher 등 ${ }^{35)}$ 은 건청 및 난청 노인들을 대상으로 순음 청력검사상 청력손실 정도와 작업기억 용량이 양이소음감소 (binaural noise reduction) 적용 시 얻는 이익을 얼마나 변화 시키는지 주관적 평가를 이용하여 분석하였다. 청력손실의 유무와 작업기억 용량의 크고 작음에 따라 나눠진 4개의 하 위 그룹에는 10 명씩 참여하였으며, 세 개의 신호대잡음비 조건 $(-4,0,4 \mathrm{~dB})$ 과 5 개의 양이소음감소 조건을 사용하였다. 그 리고 Luts 등 $^{25)}$ 의 2010년 연구에서 사용한 것과 동일한 프로 토콜을 적용하여, 각 조건 제시 후 청취 노력의 정도를 9점 척 도로 측정하였다(Fig. 5). 또한, 이 주관적 척도 평가 결과를 자극에 대한 응시 시간을 측정하는 객관적 방법인 시각 반응 시간(visual reaction time)과 비교하였다. 그러나 주관적 청 취 노력의 결과는 시각 반응 시간의 측정 결과와 일치하지
않았고, 난청 그룹이 건청 그룹보다 더 많은 노력을 보고한 이전의 다른 연구들의 결과와는 다르게 청취 그룹 간 차이가 존재하지 않았다. 그럼에도 청취 노력의 주관적 평가 결과는 양이소음감소와 청취 그룹 간 유의미한 상관관계를 보였다. 따라서 양이소음감소가 적용된 조건에서는 청취 노력이 감소 하고, 신호대잡음비가 감소할수록 청취 노력이 증가함을 확인 하였다.

주관적 및 정신생리학적 반응 모두 소음하 어음인지 검사 를 수행하는 동안 난청 그룹에서 더 높은 청취 노력이 있을 것 이라고 가설을 세운 Mackersie 등1ㅡ은 청취 노력의 정도를 분 석하기 위해 the modified version of NASA-TLX를 사용하 였다. 난청인들은 건청인들보다 소음하 어음인지 시, 피부전 도도 반응으로 입증된 교감 신경계의 높은 각성 상태와 부교 감 신경계의 높은 억제 상태를 보였다. 그러나 정신 생리학적 결과와 대조적으로, 주관적 평가에서는 난청의 영향이 없었 다. 즉, 건청 그룹과 난청 그룹 모두 인지된 노력과 정신적 수 요, 스트레스는 과제가 어려워질수록 증가하였고 인지된 수 행력은 과제가 어려워질수록 감소하였다.

Bamiou 등 ${ }^{36)}$ 의 연구에서는 정상 범주의 청력도를 갖지만 듣기의 어려움을 경험한 성인 환자들 19 명과 청각 처리 장애 (auditory processing disorder, APD)를 가진 39명의 환자들 에게 SSQ, the modified Amsterdam Inventory for auditory disability, the hyperacusis questionnaire을 실시하고 각 설문 지의 타당성을 확인하였다. 청각 처리 장애란 대뇌 수준에서 청각 처리에 어려움을 가지는 기능적 결함을 말한다. 연구 결 
Q. How much effort did it take to understand the sentences you just repeated?

\begin{tabular}{|c|c|c|c|c|c|c|c|c|c|c|}
\hline & No effort & & & & & & & & & me effort \\
\hline & 1 & & 1 & 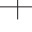 & 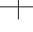 & 7 & $T$ & 1 & $T$ & $T$ \\
\hline $\mathbf{A}$ & 1 & 2 & 3 & 4 & 5 & 6 & 7 & 8 & 9 & 10 \\
\hline
\end{tabular}

Q. 따라 말한 문장을 이해하는 데 얼마나 많은 노력이 필요했습니까?

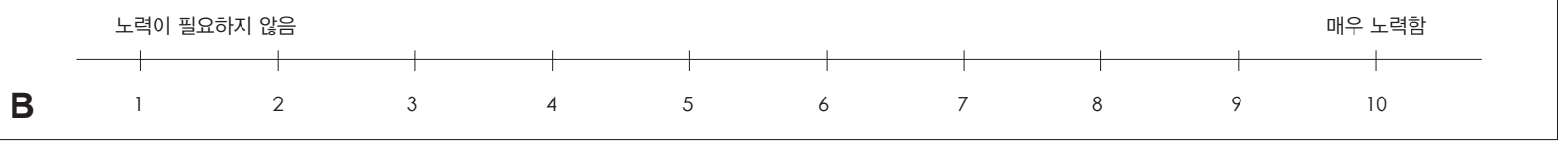

Fig. 6. 10-point scale for listening effort used by Krause, et al ${ }^{37)}$ Original version by English (A) and its translation by Korean (B).

\begin{tabular}{|c|c|}
\hline Q. Is it easy to recognize what the children were saying? & Q. 아이들이 말하는 것이 무엇인지 인지하는 것은 쉬웠습니까? \\
\hline 1. No problem, easy to decide what the word/phrase was & 1. 단어/단락이 무엇이었는지 결정하는 데 전혀 문제가 없었습니다. \\
\hline 2. Yes, I could tell what it was but I had to listen carefull & 2. 네, 나는 들은 것을 말할 수 있었지만 주의 깊게 들어야 했습니다. \\
\hline 3. I just about recognized it with a bit of a guess & 3. 나는 약간 짐작해서 그것이 무슨 말인지만 알 수 있었습니다. \\
\hline 4. Complete guess, just going by vaguely recognized bits & 4. 무슨 말인지 추측해야 했고 모호하게 약간만 알아들었습니다. \\
\hline 5. Totally unrecognizable & 5. 전부 알아들을 수 없었습니다. \\
\hline
\end{tabular}

Fig. 7. Subjective scale of ease of listening applied for Landa, et al. ${ }^{38)}$ Inferred English version (A) and its translation in Korean (B).

과, $\mathrm{APD}$ 를 가진 성인들의 듣기 어려움과 요구들은 난청을 가 진 청취자들의 것들과 어느 정도 중첩되었으나 상당한 차이 가 있었다. 따라서 $\mathrm{APD}$ 를 가진 성인들의 증상을 평가하는 데 이러한 청취 노력 설문지는 임상적으로 유용하였다.

뇌병변이 있는 환자들을 대상으로 진행한 몇몇 연구에서 도 주관적인 청취 노력의 척도를 활용하여 노력 정도를 측정 하였다. Krause 등 ${ }^{37)}$ 은 외상성 뇌 손상을 가진 9 명의 성인과 뇌 손상이 없는 6명의 성인을 대상으로 6가지 듣기 상황에서 문장을 듣고 따라 말하게 한 뒤 청취 노력의 정도를 평가하 였다. '따라 말한 문장을 이해하는 데 얼마나 많은 노력이 필 요했습니까?'라는 질문에 청취 노력의 정도를 10점 척도를 이용하여 구두로 답하였다(Fig. 6). 각 청취 상황에서 반복의 정확성은 유사하였으나, 반응 속도와 노력 정도에서는 두 그 룹 간 차이가 유의미하였다. 이는 뇌 손상의 영향을 탐지할 수 있는 복잡한 듣기 상황에서 청취 노력을 측정할 수 있음을 시사하였다. 또 다른 연구에서는 뇌성마비를 가진 사람들의 어음을 이해하는 데 필요한 청취 노력 정도와 함께 청자들의 척도 표기와 실제로 이해한 단어 비율 사이의 상관관계를 연 구하였다. ${ }^{38)}$ 각각의 듣기 상황에서 주어진 어음이 얼마나 이해 하기 어려웠는지는 5점 척도를 사용하여 평가하였다(Fig. 7). 그 결과, 경도와 심도 장애를 가진 뇌성마비 환자의 어음에 대한 주관적 청취 노력의 척도와 어음명료도 간의 강한 상관 관계가 관찰되었다. 즉, 어음 이해를 위한 주관적 노력의 정도 는 청자의 친숙성, 음성 과제의 수행, 음성 장애의 심각성과 관련이 있었고, 따라서 연구자들은 의사소통 행동의 측정 방 법으로써 이러한 주관적 청취 노력의 척도가 임상에서 사용
하기에 적합하다고 결론을 내렸다.

\section{결 론}

본 논문에서는 청취 노력의 주관적 척도를 다룬 최신 선행 논문 15 편을 중심으로 비교·분석하여 난청인의 청취 노력 을 측정하는 데 가장 적합한 측정법을 제안하고자 하였다. 많은 연구에서 다양한 척도 크기를 적용하여 대상자의 청취 노력 정도를 평가하였지만, 아직 국·내외적으로 특히 임상 에서 표준화된 검사지를 사용하기에는 세부 사용 목적이 다 르고, 장·단점이 존재하기에 하나의 획일적인 척도를 주장 하기에는 어려움이 있다. 또한 임상적으로 다수의 연구자들 은 기존에 개발된 $\mathrm{SSQ}$ 설문지를 적용하여 청취 노력을 측정 하였으나 질문 항목이 49개로 너무 많고, 질문당 척도가 10 단계로 너무 세분화되어 있어서, 환자가 직접 읽고 설문을 답하기에는 시간적으로 경제적이지 못하였다. 따라서 본 종 설 논문에서 제안하고 싶은 주관적인 청취 노력 자기보고 설 문지는 Johnson 등 ${ }^{26)}$ 의 연구에서 사용한 7점 척도이다(Fig. 2). 이 척도는 Schulte 등 ${ }^{27)}$ 의 13점 척도의 7 개 카테고리의 이 름을 척도로 사용하여 척도가 의미하는 정도를 정확히 표기 하였고, 해당 논문 내에서 청취 노력 측정 프로토콜에 추가 하기 위한 타당성 및 민감도가 증명되었다. 또한 척도점 개수 가 응답의 난이도와 변별의 정밀성에 영향을 줄 수 있다는 여러 연구 ${ }^{3940)}$ 와 관용적으로 5점 또는 7점 척도를 주로 사용 한다는 점에 비추어 볼 때, 청취 노력의 기여 정도를 선택할 수 있는 폭이 적절하다고 볼 수 있다. 
그러나 일부 연구자들이 지적하였듯이, 주관적인 청취 노 력의 측정만으로는 개인의 나이, 성격 등의 내재적 성향에 따라 과소 혹은 과대 평가될 수 있으므로 추후 연구에서 주 관적인 측정법과 객관적인 측정법 간의 상호관계를 분석하 여 주관적 측정법의 한계를 보완하는 것이 중요하겠다. 궁극 적으로는 난청인들의 청취 노력에 대한 민감도와 특이도를 반영할 수 있는 대표적인 측정 프로토콜을 정립하고 이를 임 상적 적용이 가능하도록 표준화하여, 재활 시 어음인지도와 청취 노력 정도가 적절하게 균형을 이루고 있는지 확인하는 것이 필요할 것이다.

\section{Acknowledgments}

This work was supported by the Ministry of Education of the Republic of Korea and the National Research Foundation of Korea (NRF2015S1A3A2046760).

\section{REFERENCES}

1) Park MH. The effects of FM system on speech perception of children with hearing impairment. J Speech Hear Disord 2005;14(1):43-54.

2) Hong HN. Case study of auditory training for the acquired hearing loss adult with cochlear implant. J Rehabil Res 2013;17(4):371-82.

3) Hick CB, Tharpe AM. Listening effort and fatigue in school-age children with and without hearing loss. J Speech Lang Hear Res 2002;45(3):573-84.

4) McGarrigle R, Munro KJ, Dawes P, Stewart AJ, Moore DR, Barry $\mathrm{JG}$, et al. Listening effort and fatigue: what exactly are we measuring? A British Society of Audiology Cognition in Hearing Special Interest Group 'white paper'. Int J Audiol 2014;53(7):433-40.

5) Littmann Y, Beilin J, Froehlich M, Branda E, Schäfer PJ. Clinical studies show advanced hearing aid technology reduces listening effort. Hear Rev 2016;23(4):36.

6) Desjardins JL. The effects of hearing aid directional microphone and noise reduction processing on listening effort in older adults with hearing loss. J Am Acad Audiol 2016;27(1):29-41.

7) Pals C, Sarampalis A, Baskent D. Listening effort with cochlear implant simulations. J Speech Lang Hear Res 2013;56(4):1075-84.

8) Dawes P, Munro KJ, Kalluri S, Edwards B. Acclimatization to hearing aids. Ear Hear 2014;35(2):203-12.

9) Houben R, van Doorn-Bierman M, Dreschler WA. Using response time to speech as a measure for listening effort. Int J Audiol 2013; 52(11):753-61.

10) Kramer SE, Kapteyn TS, Festen JM, Kuik DJ. Assessing aspects of auditory handicap by means of pupil dilatation. Audiology 1997;36(3): $155-64$.

11) Mackersie CL, MacPhee IX, Heldt EW. Effects of hearing loss on heart rate variability and skin conductance measured during sentence recognition in noise. Ear Hear 2015;36(1):145-54.

12) Wild CJ, Yusuf A, Wilson DE, Peelle JE, Davis MH, Johnsrude IS. Effortful listening: the processing of degraded speech depends critically on attention. J Neurosci 2012;32(40):14010-21.

13) Peelle JE, Eason RJ, Schmitter S, Schwarzbauer C, Davis MH. Evaluating an acoustically quiet EPI sequence for use in fMRI studies of speech and auditory processing. Neuroimage 2010;52(4):1410-9.

14) Gatehouse $S$, Noble W. The speech, spatial and qualities of hearing scale (SSQ). Int J Audiol 2004;43(2):85-99.

15) Brons I, Houben R, Dreschler WA. Effects of noise reduction on speech intelligibility, perceived listening effort, and personal preference in hearing-impaired listeners. Trends Hear 2014;18:

\section{4}

16) Brons I, Houben R, Dreschler WA. Perceptual effects of noise reduction with respect to personal preference, speech intelligibility, and listening effort. Ear Hear 2013;34(1):29-41.

17) Picou EM, Aspell E, Ricketts TA. Potential benefits and limitations of three types of directional processing in hearing aids. Ear Hear 2014; 35(3):339-52.

18) Schnabl J, Bumann B, Rehbein M, Müller O, Seidler H, Wolf-Magele A, et al. [Listening effort with cochlear implants: unilateral versus bilateral use]. HNO 2015;63(8):546-51.

19) Hart SG, Staveland LE. Development of NASA-TLX (task load index): Results of empirical and theoretical research. In: Meshkati N, Hancock PA, editors. Human mental workload. Amsterdam: North Holland Press;1988. p.139-83.

20) Meijer AG, Wit HP, TenVergert EM, Albers FW, Muller Kobold JE. Reliability and validity of the (modified) Amsterdam inventory for auditory disability and handicap. Int J Audiol 2003;42(4):220-6.

21) Strauss DJ, Corona-Strauss FI, Trenado C, Bernarding C, Reith W, Latzel M, et al. Electrophysiological correlates of listening effort: neurodynamical modeling and measurement. Cogn Neurodyn 2010; 4(2):119-31.

22) Erlbeck H, Kübler A, Kotchoubey B, Veser S. Task instructions modulate the attentional mode affecting the auditory $\mathrm{MMN}$ and the semantic N400. Front Hum Neurosci 2014;8:654.

23) Picou EM, Ricketts TA. Increasing motivation changes subjective reports of listening effort and choice of coping strategy. Int J Audiol 2014;53(6):418-26.

24) Rennies J, Schepker H, Holube I, Kollmeier B. Listening effort and speech intelligibility in listening situations affected by noise and reverberation. J Acoust Soc Am 2014;136(5):2642-53.

25) Luts H, Eneman K, Wouters J, Schulte M, Vormann M, Buechler M, et al. Multicenter evaluation of signal enhancement algorithms for hearing aids. J Acoust Soc Am 2010;127(3):1491-505.

26) Johnson J, Xu J, Cox R, Pendergraft P. A comparison of two methods for measuring listening effort as part of an audiologic test battery. Am J Audiol 2015;24(3):419-31.

27) Schulte M, Vormann M, Wagener K, Büchler M, Dillier N, Dreschler $\mathrm{W}$, et al. Listening effort scaling and preference rating for hearing aid evaluation [cited 2016 Oct 16]. Available from: URL: http://hearcom. eu/lenya/hearcom/authoring/about/DisseminationandExploitation/ Workshop/S2B-3_Michael-Schulte_Hearing-Aid-Scaling-Rating.pdf.

28) Mattys SL, Davis MH, Bradlow AR, Scott SK. Speech recognition in adverse conditions: a review. Lang Cogn Process 2012;27(7-8): 953-78.

29) Mishra S, Lunner T, Stenfelt S, Rönnberg J, Rudner M. Seeing the talker's face supports executive processing of speech in steady state noise. Front Syst Neurosci 2013;7:96.

30) Nachtegaal J, Kuik DJ, Anema JR, Goverts ST, Festen JM, Kramer SE. Hearing status, need for recovery after work, and psychosocial work characteristics: results from an internet-based national survey on hearing. Int J Audiol 2009;48(10):684-91.

31) Kramer SE, Kapteyn TS, Houtgast T. Occupational performance: comparing normally-hearing and hearing-impaired employees using the Amsterdam checklist for hearing and work. Int J Audiol 2006; 45(9):503-12.

32) Bess FH, Hornsby BW. Commentary: listening can be exhausting-fatigue in children and adults with hearing loss. Ear Hear 2014;35(6): 592-9.

33) Rudner M, Lunner T, Behrens T, Thorén ES, Rönnberg J. Working memory capacity may influence perceived effort during aided speech recognition in noise. J Am Acad Audiol 2012;23(8):577-89.

34) Dwyer NY, Firszt JB, Reeder RM. Effects of unilateral input and mode of hearing in the better ear: self-reported performance using the speech, spatial and qualities of hearing scale. Ear Hear 2014;35 
(1):126-36.

35) Neher T, Grimm G, Hohmann V. Perceptual consequences of different signal changes due to binaural noise reduction: do hearing loss and working memory capacity play a role? Ear Hear 2014;35(5):e213-27.

36) Bamiou DE, Iliadou VV, Zanchetta S, Spyridakou C. What can we learn about auditory processing from adult hearing questionnaires? J Am Acad Audiol 2015;26(10):824-37.

37) Krause MO, Kennedy MR, Nelson PB. Masking release, processing speed and listening effort in adults with traumatic brain injury. Brain Inj 2014;28(11):1473-84.
38) Landa S, Pennington L, Miller N, Robson S, Thompson V, Steen N. Association between objective measurement of the speech intelligibility of young people with dysarthria and listener ratings of ease of understanding. Int J Speech Lang Pathol 2014;16(4):408-16.

39) Cox EP III. The optimal number of response alternatives for a scales: a review. J Mark Res 1980;17(4):407-22.

40) Kim NK. An comparative analysis of item selection methods for the development of the Likert scale [dissertation]. Seoul: Yonsei Univ.; 2001.

\section{정답 및 해설}

답 (3)

해 설 비중격 농양은 CT를 통해 진단할 수 있어 조직검사가 필요하지 않으며, 치료는 절개배농으로 대부분 잘 치유된다. 비중격 혈종의 화농과 외상에 의해서 발생하는 경우가 대부분이고, 드물게 외상 없이도 비전정염, 치성감염과 같은 주위 조직의 감염이나 면역이 저하된 경우에도 발생할 수 있다(대한이비인후과학회. 이비인후과학 두경부외과학 교과서. 서울: 일조각; 2009. p.1081-5). 